\title{
Accounting information system and management's decision making process
}

\author{
Farhad Hanifi ${ }^{* a}$ and Asgar Taleei ${ }^{\mathrm{b}}$
}

\begin{abstract}
${ }^{a}$ Assist. Prof. \& Faculty Member, Department of Accounting, School of Management and Human Sciences, Tehran Center Branch, Islamic Azad University (IAU), Tehran, Iran

${ }^{b}$ M.Sc. Student, Department of management, School of Management and Human Sciences, Tehran Center branch, Islamic Azad University (IAU), Iran

C H R O N I C L E A B S T R A C T

In this paper, we address the management's decision making process and examine the effect of accounting information system (AIS) in PARS GARMA holding organization in making sound and effective decisions and inform the reader on how AIS influences on the management decisions in 6 major perspectives including quality, accuracy, economic, validity, speed and on time concepts. The major source of data to this research is primary data through the administration of questionnaires. Regression and correlation analysis was used for the data analysis. The findings show that accounting information system had a significant and positive role in PARS GARMA holding management decisions process in several perspectives but AIS had no significant impact on speed of decision making.
\end{abstract}

\begin{tabular}{l}
\hline Article history: \\
Received January 25, 2015 \\
Received in revised format 28 \\
March 2015 \\
Accepted 7 May 2015 \\
Available online \\
May 102015 \\
\hline Keywords: \\
Accounting information system \\
Management decision making \\
Process \\
PARS GARMA Construction and \\
Industrial Holding
\end{tabular}

\section{Introduction}

Making decisions is part of our every day's lives and it is often one of the main functions of management. Indeed, management and decision-making are often considered as an integrated tasks and management usually makes the major decisions of the organization (Young, 1982). Decision making process involves the selection of the best course of actions (Emmanuel et al., 1990). In order to decide on the best option, management has to judge the effectiveness of various alternatives based on some data (Bierman et al., 1986). For this reason, they often depend on financial and economic information gathered by management accounting. Management information system is indispensable tool for decision making process in today's turbulent world. Today, organizations are advised to invest on information technology tools as it improves their efficiency, effectiveness and their overall performance. In addition, accounting information system (AIS) plays the key role in management decision making in today business word. Nowadays, organizations try to have efficient AIS in our business activities.

\footnotetext{
* Corresponding author. Tel: +982188628019

E-mail address: aminshakourloo@yahoo.com (F. Hanifi) 
In this paper, we try to know about AIS impact in our case study to learn whether or not AISs that are used by a firm, PARS GARMA industrial and construction holding, could influence on 6 various aspects of management decision-making process. In this paper, as a start point, the methodology will provide the reader with an insight into the process of how the study was conducted. Afterwards, the chosen theories are introduced, which include ideas of various accounting tools as well as decision making.

In recent years, the advancement in information system modules all over the world has helped business firms exert resources in this area to get power for compete favorably among their local and foreign counterparts, more effectively. Today, most modern business organizations find themselves in the atmosphere of global uncertainties, high competition levels locally and internationally and unprecedented change in the economy. Hence, a great demand is often placed on from the managers of these organizations to make suitable and informed decisions (Copeland \& Dascher, 1978).

The information of the economic systems is mostly provided by the economic evidences or databases. Zare and Shahsavari (2012) mentioned that most parts of information in organizations are accounting information. This statement sustained by the fact that the accounting information systems include components and elements of an organization, which provides information for users by processing financial events. Based on the accounting information function, which is used to provide information for making substantiate decisions, and considering the two components of accounting, financial and managerial accounting, we can assert that accounting has an internal information function, for the enterprise management, and an external one, for the third parties. Internal decision-making and analysis of cause and effect relationships can require very specific models and accounting information (Eierle \& Wolfgang, 2013). Because managers should obtain high quality and suitable information from formal and informal channels for decision making (Zare et al., 2013), and because financial accounting information is regarded insufficient (Eierle \& Wolfgang, 2013), the managerial accounting may provide information underlie the decision making both inside and outside the enterprise. Accountants play a crucial role in providing information for making economic and financial decisions. These decisions are essential elements for the organizations. Implementing the wrong ones can affect the company in a very negative way and may sometimes lead to its bankruptcy.

Accounting information also may help managers understand their tasks more clearly and reduce uncertainty before making their decisions (Choe, 1996). Thus, AIS is vital for all organizations and every organization, either profit or non-profit, needs to maintain an AIS, carefully. Accounting system, in recent years, is considered as a system of information, which is not limited to the data and financial information, but it includes data and descriptive and quantitative information which is useful in decision making for users. Such users include present and potential investors, suppliers, lenders, creditors, customers, governments and the public in conjunction with the administration, which is its responsibility to prepare the accounting programs and displaying it, this information must be capable of achieving the firms' objectives. Hence the role of AIS for effective decision making cannot be disregarded. It is noteworthy to mention here that AIS derives its source from accounting data. AISs produce results which enhances decision making. Hence, it can safely be concluded that AIS is not an end in itself but a tool to an end i.e. decision making to improve corporate performance. AIS is capable of producing comprehensive accounting information, which are invaluable basis for making important decisions.

In order to circumvent financial disasters through false and ineffective decisions, there is a big pool of financial tools, which are available to support the decision making process. Nevertheless, accounting tools implemented vary from one firm to another. One tool that proved to be very effective in one firm might fail for another one. Different information are needed for these diverse purposes, therefore organizations have to concentrate on various accounting tools to support their decisions-making process. PARS GARMA applies its own tools and techniques and presently, the company is operate, 
quite successfully, as its position as Iranian's market leader shows. Hence, it can be assumed that without making the right decisions this position would hardly be possible. Management accounting tools applied in PARS GARMA might have contributed to some extent to these beneficial decisions.

\section{Literature review}

Accounting information system is considered as a subsystem of Management Information System (MIS). For the first time in 1966 the Statement of Basic Accounting Theory, published by the American Institute of Certified Accountant (AICPA) stated that "Accounting actually is information system and if we be more precise accounting is the practice of general theories of information in the field of effective economic activity and consists of a major part of the information which is presented in the quantitative form”. In this statement, accounting is part of general information system of an economic entity. Hence, AIS could be described as systems applied to record the financial transactions of a firm. These systems combine the methodologies, controls and accounting techniques with the technology of the information technology (IT) industry to track transactions provide internal reporting data, external reporting data, financial statements, and trend analysis capabilities to influence on organizational performance (Grande et al., 2010).

According to Boocholdt (1999), AIS can be described as systems that operate functions of data gathering, processing, categorizing and reporting financial events with the objective of providing relevant information for the purpose of score keeping, attention directing and decision-making. AIS, according to Nicoloau (2000), is a computer based system that increases the control and enhances the cooperation within the firm. Management is engaged with various types of activities with different quality components. They require also non-financial information such as production statistics, quality of production, etc. However, quality of information generated from AIS is very important for management. Kim (1989) argued that usage of AIS depends on the perception of the quality of information by the users. Generally the quality of information depends on the reliability, form of reporting, timeliness and relevance to the decisions. Effectiveness of AIS also depends on the perception of decision makers on the usefulness of information generated by the system to satisfy informational requires for operation processes, managerial reports, budgeting and control within the organization. Some studies indicate that the effectiveness of AIS depends on the quality of output information that satisfy the users (Cameron, 1986; Lewin \& Minton, 1986; Quinn \& Rohrbaugh, 1983; Delone \& Mclean, 1992; Kim, 1989). AIS are considered essential organizational mechanisms that are necessary for effectiveness in decision management and control in organizations (Zimmerman, 1995). AISs will be useful when information provided by them is applied effectively for decision making process by the users. Otley (1980) argued that accounting systems are an important part of the fabric of organizational life and the have to be evaluated in their wider managerial, organizational and environmental context. Therefore, the effectiveness of AIS not only depends on the purposes of such systems but also depends on contingency factors of each organization. AIS are said to be effective when the information provided by them serves widely the system users' needs. Effective systems should systematically provide information, which has the necessary potential effective on decision making process. The effectiveness of AISs has long been a subject of many researches (Choe, 1996; Chenhall \& Kim, 1989).

Existing literature offers scant evidence of the relationship between these AIS and financial performance. Recently, many studies have confirmed that AIS plays a proactive role in the strategy management, acting as a mechanism that empower organizational strategy (Chenhall, 2003). Strategy has been investigated using various typologies by Porter (1985) or Miles and Snow (1978). The latter has been extensively implemented in management literature (Zajac \& Pearce, 1990). There have been also several studies on the aspect of value relevance. Ball and Brown (1968) provided some evidence about security market reaction to earnings announcements. On the basis of their studies, they stated that accounting information could be a useful tool for investors in forecasting the expected values and risks 
of security returns and the results showed that earnings were value relevant. In 1967, Benson worked on published corporate accounting data and stock prices and claimed that published accounting reports were applied by investors to evaluate their expectations of the corporations. He also posits that changes in investors' expectation caused by published accounting data should be reflected in a price of firms on stock market. This wok was criticized by Parker (1967) because the cause-effect relationship was difficult to isolate.

Pankoff and Virgil (1970) presented an inventive and ambitious laboratory experiment to compute the usefulness of accounting and other information to professional security analyst who participated as subjects in the laboratory stock market. Usefulness of information is defined as "the extent to which information facilitates decision making”. Based on this definition they presented five methods to appraise usefulness of information item. They are subject's demand for the item; the degree to which the item influences on the subject's forecast; the extent to which the item leads to good forecasts; the degree to which the item affects the subject's decisions and the extent to which the item leads to good decisions.

\section{Research Methodology}

Our main strategy in the research analysis was a case study analysis, which could be a good way to develop and increase understanding of a complex system and it can add more experiences and opinions to the knowledge gained in previous studies. A case study research offers the chance of a holistic view and various aspects are studied in relation to each other and within their context. So the holistic view sees more for the whole than just the sum of its parts (Gummesson, 2000; Yin, 2003). Among the drawbacks are a lack of statistical reliability and validity, because case studies are often not based on a random numbers of observations and random selection of cases. Moreover, we cannot draw generalizations from one case. However, our aim is neither to depict generalizations nor to conduct this study by using several cases (Gummesson, 2000). Rather, we would like to observe one company, PARS GARMA and find out about the application of accounting tools in this particular organization. Both, quantitative as well as qualitative data collection methods can be used within a case study. According to Yin (2003), case study can make use different sources, like documentation, archival records, interviews, direct observations, participant observation. The population of study consists of all managers that engage in decision making process and utilize accounting information for their practices in the PARS GARMA holding company that operates in Iran. The sample size is calculated as follows,

$$
N=Z_{\alpha / 2}^{2} \frac{p \times q}{e^{2}}
$$

where $N$ is the sample size, $p=1-q$ represents the probability, $z_{\alpha / 2}$ is CDF of normal distribution and finally $\varepsilon$ is the error term. For our study we assume $p=0.5, z_{\alpha / 2}=1.96$ and $e=0.05$, the number of sample size is calculated as $N=115$. In this study, 115 key managers across the PARS GARMA holding company were chosen. These are specifically the managers who employed AIS in carrying out their job responsibilities and decisions. Method of data collection in carrying out this research work, data was collected from major primary sources. The primary source of data was the questionnaire, which was carefully framed and administered to a sample of 115 respondents in the organizations selected. The questions in the questionnaire are straightforward and close ended questions. Hence, responses from the questionnaire were on the five point Likert-type questions (agreed, strongly agreed, disagreed, strongly disagreed and indifferences). The questionnaire consisted of twenty questions, which were carefully designed to collect relevant data. The research instrument was pilot studied, by expert panel including faculty members. The revised instrument and a cover letter were mailed to the specific individuals who were listed as the financial managers of the firms sampled. A reminder was sent and non-respondents were followed up with two additional mailings. During the first questionnaire launching, 94 questionnaires were completed and returned. In the second and third mailings, a total of 
13 more completed questionnaires were returned. Altogether 106 questionnaires were available for data analysis.

\section{Research results}

In this section we show our research main results in two distinct subsections:

\subsection{Descriptive Statistics}

Fig. 1 shows descriptive statistics in two main different figures in terms of age and education.



Age

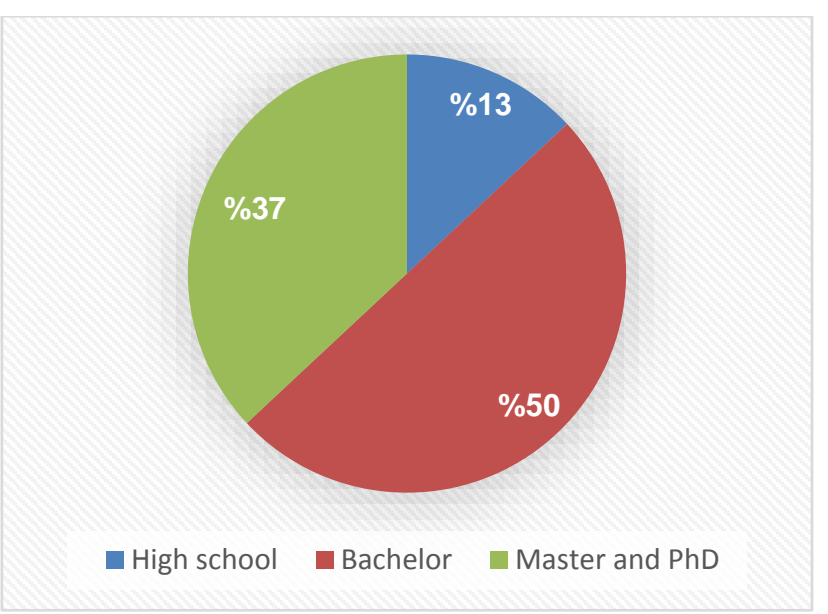

Years of education

Fig. 1. Personal characteristics of the participants

As seen in Fig. 1 the respondent of age group from 26 to 35 years range have the most frequency with 40 percent and group of age range between 36 and 45 has been placed in next stage, respectively. On the other hand, the group of ages under 25 years placed as least frequency between different ages variable group. After age variable we show educational level variable in table1. According to educational level variable demonstration in Fig. 1 it is evident that about 40 percent of research sample includes people with bachelor degree that is the most frequency in our sample. Also master and $\mathrm{PhD}$ degree with 30 percent frequency are in the next stage respectively whereas the least education degree frequency groups among research educational groups are people with high school education degree.

Table 1

Respondent answering level to research variable Descriptive Statistics

\begin{tabular}{ccccc}
\hline & Mean & S.V & Max & Min \\
\hline Quality & 3.097 & 0.608 & 4.20 & 1.80 \\
Speed & 3.365 & 0.702 & 4.75 & 1.50 \\
Accuracy & 3.43 & 0.669 & 4.50 & 1.50 \\
Validity & 3.26 & 4 & 4 & 1.75 \\
Economic & 3.29 & 0.768 & 4.75 & 1 \\
Info output & 3.187 & 0.612 & 4.20 & 1.40 \\
On time & 3.36 & 0.549 & 4.25 & 2.25 \\
\hline
\end{tabular}

As we can see from the results of Table 1 the level of responses to research variable are higher than the average, approximately. 


\subsection{Statistical analysis}

In this subsection our main focus is on analysis of gathered data about reliability of our variables. For reliability analysis we used outward loads analysis method in the first stage for each factor and Fig 2 shows the results our survey.

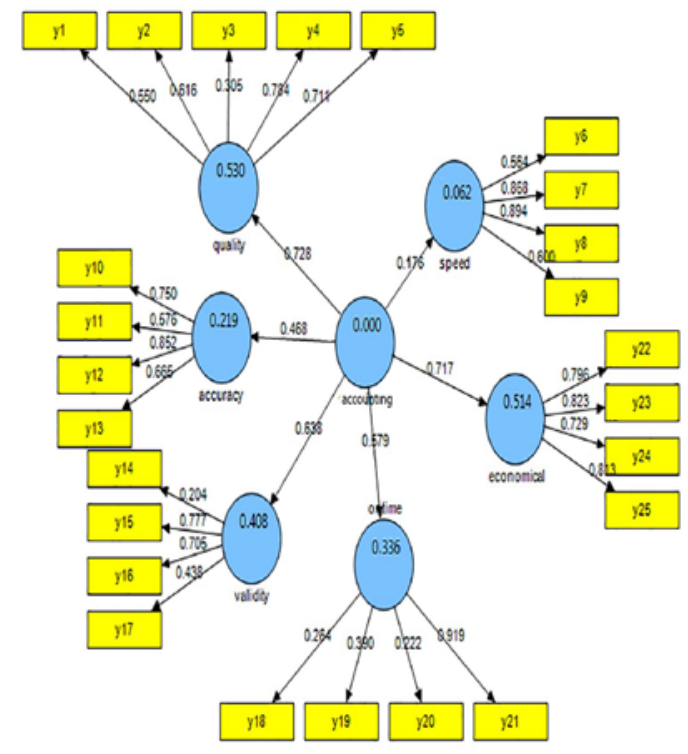

Fig. 2. Research model in path coefficient mode

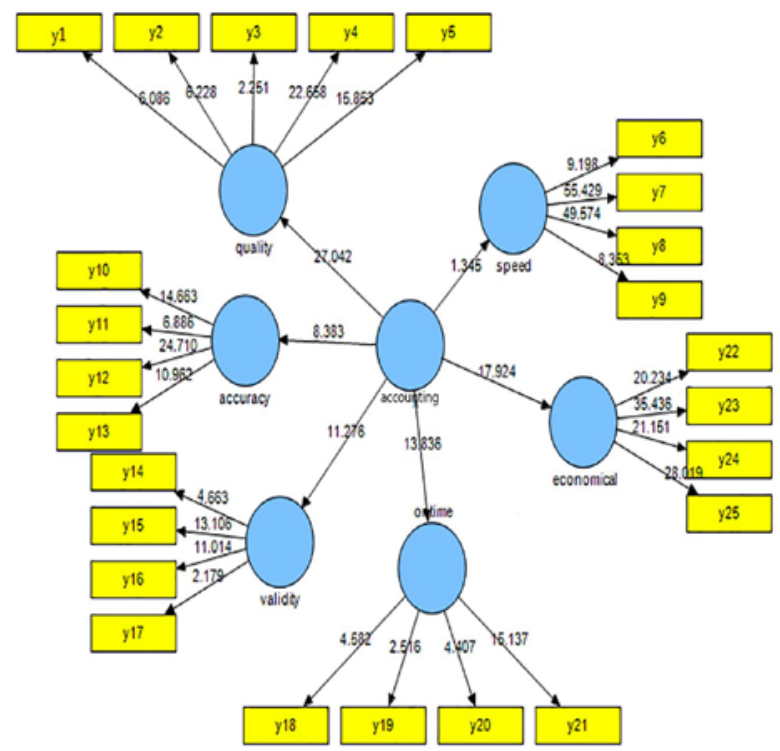

Fig. 3. Research variables factor loading significance

As we can see, each factor located in the condition that coincides on their components. Moreover, investigation for the second criteria about item reliability of the survey are shown in Fig. 3. As seen in Fig. 3, $t$ statistics amounts related to factorial loads obtains values higher than 1.96 for significant in 0.05 levels. Table 2 shows the general results of research components.

Table 2

General results of research components

\begin{tabular}{lccc}
\hline Variables & Average & Compound Credit & $R^{2}$ \\
\hline Quality & 0.67 & 0.74 & 0.530 \\
Speed & 0.55 & 0.83 & 0.062 \\
Accuracy & 0.52 & 0.81 & 0.219 \\
Validity & 0.54 & 0.63 & 0.408 \\
On time & 0.58 & 0.72 & 0.336 \\
Economical & 0.63 & 0.87 & 0.514 \\
Info Output & 0.53 & 0.78 & - \\
\hline
\end{tabular}

According to Table 2, amounts under compound credit column is Dilvan-Goldashtain coefficient that is acceptable only for higher than 0.7 amounts. Obviously amounts under averages column obtain values higher than 0.05 . After mentioned previous analysis we show variables correlation in Table 3.

\section{Table 3}

Research variables correlation matrix

\begin{tabular}{cccccccc}
\hline & Info output & Accuracy & Economical & On time & Quality & Speed & Validity \\
\hline Info Output & 0.728 & & & & & & \\
Accuracy & 0.468 & 0.721 & & & & & \\
Economical & 0.717 & 0.461 & 0.794 & & & \\
On time & 0.579 & 0.489 & 0.571 & 0.762 & & \\
Quality & 0.728 & 0.388 & 0.472 & 0.625 & 0.819 & 0.742 & 0.735 \\
Speed & 0.676 & 0.248 & 0.508 & 0.496 & 0.713 & 0.530 & 0.688 \\
Validity & 0.639 & 0.361 & 0.497 & 0.503 & & & \\
\hline
\end{tabular}




\subsection{The summary of the structure of the proposed study}

After the analysis about research measurement model, we survey the research structural model thorough Beta coefficient and $\mathrm{R}^{2}$ value analysis and Fig. 4 show the analysis of the results.

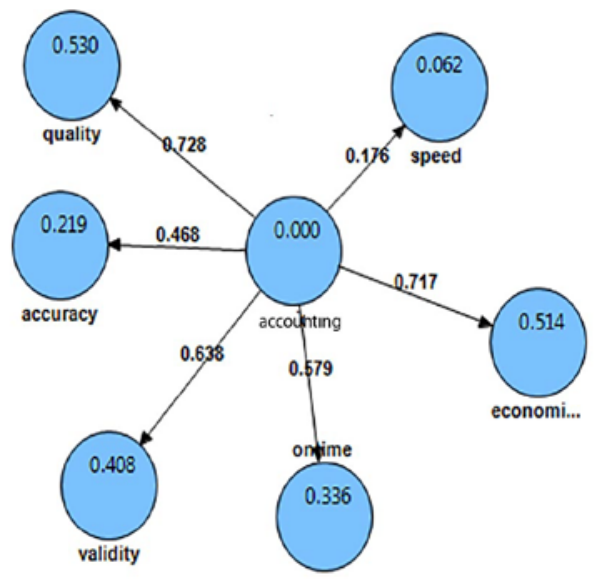

Fig. 4. Research structural model in standard mode

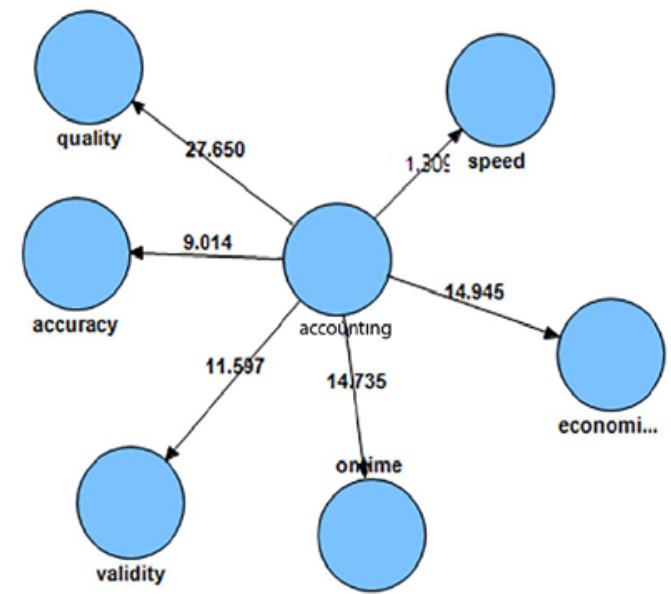

Fig. 5. The results of t statistics amounts on path lines after Bootstrap Hypothesis Test

From Fig. 4, it is clear that decision quality coefficient is 72 percent, which means that decision making variable predicts 72 of own factors. These amounts for speed variable is about $17 \%$, which also means that this variable predicts 17 percent of its own factors. These amounts for accuracy, validity, on time and economic factors are 46, 63, 57 and 71 percent, respectively. The path coefficient shown in Fig 4, shows that the effect of information output on decision making quality is 0.053 percent and $0.62,0.219$, $0.408,0.336,0.514$ percent for speed, accuracy, validity, on time and economic variables, respectively. These following results can be realized from Fig. 5:

First of all, Beta coefficient amount for the first path, impact of information output on decision quality, is 27.650>1.96 and zero hypothesis is rejected for quality of decision making process. So we can say information output in PARS GRAMA holding had positive effect on managers' decision making. Secondly, Beta coefficient for the second path, impact of information output on decision making speed, is 1.309 , which is less than 1.96. So we can say information output in PARS GARMA holding had no positive effect on speed of decision making in this organization and zero hypothesis was accepted for speed of decision making process in this study. Finally, Beta coefficient amount for the third path, impact of information output on decision making accuracy, is 9.014, which is higher than 1.96. So we can say information output in PARS GARMA holding had significant positive effect on accuracy of decision making in this organization. Moreover, Beta coefficients for validity, on time and economic variables are 11.597, 14.735 and 14.945, respectively and these amounts mean that information output in PARS GARMA holding had significant positive effect on other three variables of decision making in this organization and we can say confidently that zero hypothesis have been rejected for these three variable. We show brief result of $\mathrm{R}$ square analysis in Table 4 as follows,

\section{Table 4}

Research model brief R square analysis

\begin{tabular}{lllllll}
\hline Model & $\begin{array}{l}\text { Predicted } \\
\text { variables }\end{array}$ & $\begin{array}{l}\text { Predicting } \\
\text { variables }\end{array}$ & $\begin{array}{l}\text { Path } \\
\text { coefficient }\end{array}$ & T statistics & Hypothesis & Final result \\
\hline 1 & Quality & & 0.728 & 27.042 & $\mathrm{H}_{1}$ & accepted \\
2 & Speed & Accounting & 0.176 & 1.345 & $\mathrm{H}_{2}$ & rejected \\
3 & Accuracy & system & 0.468 & 8.383 & $\mathrm{H}_{3}$ & accepted \\
4 & Validity & information & 0.638 & 11.276 & $\mathrm{H}_{4}$ & accepted \\
5 & On time & output & 0.579 & 13.836 & $\mathrm{H}_{5}$ & accepted \\
6 & Economic & & 0.717 & 17.924 & $\mathrm{H}_{6}$ & accepted \\
\hline
\end{tabular}




\subsection{The results of testing hypotheses}

As mentioned before we analyze the main hypothesis as follows,

$\mathrm{H}_{0}$ : There is no significant relationship between accounting information system and effective decision making in PARS GARMA construction and industrial holding.

$\mathrm{H}_{1}$ : There is significant relationship between accounting information system and effective decision making in PARS GARMA construction and industrial holding.

We have used regression analysis to analyze this hypothesis. The result and conclusion reached were shown in Table 5 as follows,

Table 5

Research main model fitness

\begin{tabular}{ccccc}
\hline Model & $\mathrm{R}$ & $\mathrm{R}^{2}$ & $\mathrm{R}_{\text {adj }}^{2}$ & $\begin{array}{c}\text { Standard error } \\
\text { estimation }\end{array}$ \\
\hline 1 & 0.726 & 0.527 & 0.521 & 0.328 \\
\hline
\end{tabular}

Table 6 shows the results from relationship analysis between the research independent and dependent variables. As seen in the table the correlation amount between two accounting information output and management decision making variables is 0.726 , which shows significant relationship between these two variables. The $\mathrm{R}^{2}$ coefficient is equal to 0.527 and shows that accounting information system variable can determine 52.7 percent of management decision making as dependent variable. Table 6 shows variation analysis of our model:

Table 6

Research model variation analysis

\begin{tabular}{lcccc}
\hline Model & Sum squares & Freedom level & F & Sig. Value \\
\hline Regression & 9.652 & 1 & 89.525 & 0.000 \\
Remain & 8.651 & 113 & & \\
\hline All & 18.303 & 114 & & \\
\hline
\end{tabular}

Table 7 shows regression impact factor coefficients of accounting information system outputs on management's decision making.

Table 7

The summary of regression analysis

\begin{tabular}{lccccc}
\hline Model & Beta & S.D. & t & Meaning level & Hypothesis \\
\hline $\begin{array}{l}\text { constant } \\
\begin{array}{l}\text { Accounting } \\
\text { information output }\end{array}\end{array}$ & 0.726 & 0.194 & 7.761 & 0.000 & - \\
\hline
\end{tabular}

According to the results of Table 7, the constant gave a $t$ value of 7.761, which is the intercept, hence establishing a positive relationship because of the positive value while the row contains the name of the independent variable, AIS, which refers to the slope. The table also shows the $t$ statistics which helps us determine the relative importance of each variable in the model. The value for the independent variable is statistically significant and this also explains the establishment of a relationship between the independent variable and the dependent variable. The independent variable, AIS, had a significant value of 0.000 , which is lower than the decision rule value of 0.05 . In addition, this explains for the strong relationship that existed among the variables. Therefore, we can conclude that there was a significant relationship between effective decision making and accounting Information system. 


\section{Conclusion}

This study has presented an empirical investigation to evaluate the effectiveness of accounting information systems (AIS) in management decision making in terms of various perspectives: better economic decision-making by managers, efficient accuracy, suitable speed, high validity and on time concepts of management decision making transaction processes. The findings of the research have indicated that implementation of accounting information systems could lead to better decision-making by managers as whole, more effective internal control systems, enhancement of the quality of financial reports and facilitating financial transaction processes in PARS GARMA industrial and construction company. Organizations are encouraged to embrace the effective use of accounting information system in order to enhance and to improve their competitive advantage in this turbulent 21st century.

Like all empirical studies, the present research also has its own limitations due to the methodology employed. Use of questionnaire to collect data always has also its own limitations, since responses could be biased because of the common method used for the collection of all data. Although extensive care has been taken when designing the questionnaire and the pilot study refined the questions, still the criticism of the survey method can never be completely ignored and should be taken into account.

Measuring research questions based on the respondents' opinions would limit our generalization of the findings. However, the above mentioned constraint will not invalidate the findings of the study. Despite the above limitations, this research has provided useful results in paving the way for future research in this area.

This research could provide a supportive evidence for the implementation of AIS. Avenues for future research could be:

1. Analysis of the effectiveness of AIS with corporation of AIS designer companies,

2. Analysis of the effectiveness of AIS as a part of MIS,

3. Study of the extent to which factors such as inflation, human resource accounting etc. would be taken into account when designing an AIS, and the effects of user participation on the design of AIS.

\section{Acknowledgement}

The authors would like to thank the anonymous referees for constructive comments on earlier version of this paper.

\section{References}

Bierman, H., Bonini, C. P., \& Hausman, W. H. (1991). Quantitative analysis for business decisions. Homewood, IL: Irwin.

Boockholdt, J. L. (1995). Accounting information systems: transaction processing and controls. McGraw-Hill Professional.

Cameron, K. (1986). A study of organizational effectiveness and its predictors. Management Science, 32(1), 87-112.

Chenhall, R. H., \& Morris, D. (1986). The impact of structure, environment, and interdependence on the perceived usefulness of management accounting systems. Accounting Review, 61(1), 16-35.

Choe, J. M. (1996). The relationships among performance of accounting information systems, influence factors, and evolution level of information systems. Journal of Management Information Systems, 12(4), 215-239.

Copeland, R. M., Dascher, P. E., \& Davison, D. L. (1980). Financial accounting. John Wiley \& Sons. 
Delone, W. H., \& Mclean, E. R. (1992). Information System success: the Quest of the Dependent variable. Information Systems Research, 3, 60-95.

Eierle, B., \& Schultze, W. (2013). The role of management as a user of accounting information: implications for standard setting. Journal of Accounting and Management Information Systems.

Emmanuel, C., Otley, D., \& Merchant, K. (1990). Accounting for management control (pp. 357-384). Springer US.

Grande, E. U., Estébanez, R. P., \& Colomina, C. I. M. (2011). The impact of accounting information systems (AIS) on performance measures: empirical evidence in Spanish SMEs. The international journal of digital accounting research, 11(17), 25-43.

Gummesson, E. (2000). Qualitative Methods in Management Research. $2^{\text {nd }}$ ed., Thousand Oaks, Calif.: Sage publications.

Kim, K. (1989). Uses satisfaction: A synthesis of three different perspectives. International Journal of Accounting Information Systems, 6, 85-99.

Lewin, A. Y., \& Minton, J. W. (1986). Determining organizational effectiveness: Another look, and an agenda for research. Management science, 32(5), 514-538.

Nicolaou, A. I. (2000). A contingency model of perceived effectiveness in accounting information systems: Organizational coordination and control effects. International Journal of Accounting Information Systems, 1(2), 91-105.

Hayes, D. C. (1977). The contingency theory of managerial accounting. Accounting review, 52(1), 2239.

Quinn, R. E., \& Rohrbaugh, J. (1983). A spatial model of effectiveness criteria: Towards a competing values approach to organizational analysis. Management science, 29(3), 363-377.

Yin, R. K. (2013). Case study research: Design and methods. Sage publications.

Young, J. F. (1982). Decision-making for Small Business Management. $2^{\text {nd }}$ ed., Florida, Robert E. Krieger Publishing Company.

Zare, I., Nekounam, J., Pirzad, A., Sedaghatjoo, F., \& Mosavimoyahar, S. (2013). Role of accounting information systems on relevance of accounting information. Life Science Journal, 10(3s).

Zare, I., \& Shahsavari, A. (2012). Ability of Accounting Information to Anticipate Risk. American Journal of Scientific Research, 49, 5-10.

Zimmerman, J. (1997). Accounting for Decision making and control. Boston: Irwin/McGraw Hill. 